\title{
A Comparative Prospective Study of Platelet Rich Plasma vs. Corticosteroid Injection in Plantar Fasciitis not Responding to 6 Weeks of Conservative Treatment
}

\author{
Nishanth Shetty*, Vikram Shetty and Siddharth Shetty \\ K.S. Hegde Medical Academy, Mangalore, India
}

*Corresponding author: Nishanth Shetty, K.S. Hegde Medical Academy, Mangalore, India, E-mail: ynshetty@gmail.com

\begin{abstract}
Background: Plantar fasciitis is the most common cause of heel pain and can is a challenge to treat in the everyday practice of an orthopedician [1].

There are various modalities for the treatment of plantar fasciitis that include rest, orthotics, night splints, extracorporeal shockwave therapy and casting [2]. If all conservative methods fail; a corticosteroid injection over the medial tuberosity of the calcaneum is an effective treatment modality. In recent years the use of Platelet Rich Plasma (PRP) a component of blood that is bioactive with a platelet concentration 2-5X the baseline platelet count of the patient [3]. $\mathrm{PRP}$ is said to act as rally point by attracting inflammatory mediators and cytokines allowing the deposition of collagen, collagen maturation and remodeling [4]. This has been the reason for the increased interest in its use for plantar fasciitis.

We have compared two modalities of treatment in our study, PRP injections and corticosteroid injections in the treatment of plantar fasciitis not responding to 6 weeks of conservative therapy.
\end{abstract}

Aims and objectives:

- To study and compare the results of corticosteroid injections in people with plantar fasciitis who were not better with 6 weeks of conservative treatment.

- To study and compare the results of PRP injections in people with plantar fasciitis who were not better with 6 weeks of conservative treatment.

- To study and compare the results of corticosteroids and PRP for the treatment of Plantar Fasciitis.

- To asses any complications in the above-mentioned groups.

Materials and method:

Study Type: Comparative Prospective study.
Source: All patients with Plantar Fasciitis, who were not better with 6 weeks of conservative treatment who presented to the orthopedic department of Justice K.S. Hegde Charitable Hospital from August 2014 to Oct 2016, were included in the study after explaining the procedure and with consent. All the patients were assessed according to the VAS and the AOFAS score which was taken before the injection and at 3 weeks, 6 weeks and at 6 months.

Sample size: 50 patients were selected with 25 in each of the group.

Sample selection: The treatment method is decided by the patient after explaining both the procedures.

Statistical analysis: Intragroup comparison by Paired $T$ Test and Intergroup comparison by student $\mathrm{T}$ test.

Results: Both groups were evaluated subjectively and functionally before the respective injection and then evaluated on follow up at 3 weeks, 6 weeks and 6 months with the same scoring systems.

We concluded that both PRP and corticosteroids injections both provide symptomatic relief in the treatment of plantar fasciitis both functionally and subjectively; results at 6 months are suggestive that PRP injections provided better functional results.

\section{Introduction}

Plantar fasciitis is one of the most common causes of heel pain that an orthopedician faces in the outpatient department [1]. It is a degenerative pathology rather than an inflammatory process and in chronic forms can prove quite difficult to treat [5].

Microscopic tears occur in the plantar fascia due to the windlass mechanism that exists. This is a combination of repeated opposing forces that act on the fascia

Citation: Shetty N, Shetty V, Shetty S (2018) A Comparative Prospective Study of Platelet Rich Plasma vs. Corticosteroid Injection in Plantar Fasciitis not Responding to 6 Weeks of Conservative Treatment. Int J Foot Ankle 2:008.

Accepted: July 17, 2018; Published: July 19, 2018

Copyright: (c) 2018 Shetty N, et al. This is an open-access article distributed under the terms of the Creative Commons Attribution License, which permits unrestricted use, distribution, and reproduction in any medium, provided the original author and source are credited. 
by the action of the tendoachilles and the forefoot. This results in a cumulative cellular damage that is exaggerated by chaotic vascularity. The fascia develops zones of hyperplasia and hypoplasia [6]. Various modalities employed for treating plantar fasciitis conservatively are night splinting, orthotics, stretching exercises and extracorporeal shockwave therapy [2].

Corticosteroids injections have been used to treat plantar fasciitis and are an effective modality for pain relief. Literature has shown evidence of complications associated with corticosteroids injections such as fascial rupture $[7,8]$. PRP due to its autologous nature is thought to be a safer alternative with less effect on the biochemical function of the foot [9].

This study will help us in deter which amongst the two treatments is more effective both subjectively and functionally.

\section{Aims}

- To study and compare the results of corticosteroid injections in people with plantar fasciitis who were not better with 6 weeks of conservative treatment.

- To study and compare the results of PRP injections in people with plantar fasciitis who were not better with 6 weeks of conservative treatment.

- To study and compare the results of corticosteroids and PRP for the treatment of Plantar Fasciitis.

- To asses any complications in the above-mentioned groups.

\section{Need for the study}

This study was done to check the objective and subjective scoring of patients treated by corticosteroids and PRP and their effectiveness in treating plantar fasciitis. We aim to conclude which of the two injections is the most effective modality of treatment with least occurrence of complication.

\section{Review of Literature}

Plantar fasciitis presents as severe pain in the heel after a period of rest or with the first steps of the day which alleviates with movement of the foot [10].

The exact etiology of the condition is not known but it is postulated that it is mainly caused due to overloading of the plantar foot muscles. These muscles include the adductor hallucis, quadratus plantae, flexor digitorum brevis and abductor digiti minimi quanti all of which originate from the medial calcaneal tuberosity [11].

The risk factors for developing plantar fasciitis include obesity, flat feet, limb length discrepancy and overuse. Tightness of the tendoachilles and inappropriate foot wear has also proven to cause plantar fasciitis [12].

The plantar fascia is a collective bundle containing three collagenous fibers. The thickest are the central fibers flanked on either side by the narrow medial and lateral portions. This divides into two stratums the superficial and deep stratums which are attached into the skin of the transverse sulcus that separates the toes form the sole and the deeper stratum. It further divides into two components that go on either side of the flexor tendons of the toes and blends with the transverse metacarpal ligament. The basic function is to support the arch of the foot by acting as a tie rod which develops tension with the foot bears weight.

During the gait cycle the plantar fascia is elongated in the contact phase becoming tense due to the shortening of the foot and elevation of the longitudinal arch. This is similar to a windlass, where the plantar fascia is the cable, the metatarsal head the drum and the handle the proximal phalanx $[12,13]$. High calcaneal pressures and repeated opposing traction of the tendoachilles along with the windlass effect cause microscopic tears in the plantar fascia [14]. These micro-tears in the fascia causes breakdown of collagen and scarring within the fascia [15].

Diagnosis is aided by a lateral radiograph of the ankle. It helps assess the thickness of the plantar fascia and the presence of a heel spur. It can also be used to determine the quality of the fat pads of the heel. X-ray will also rule out stress fractures, unicameral bone cysts and giant cell tumors.

Ultrasonography (USG) is another noninvasive and cheap investigation used to locate and diagnose this chronic tendinopathy. Though, it depends on the sonologist's experience and ability [16]. USG will show thickened plantar fascia which is usually 2-4 mm.

MRI may also be useful thought more expensive but when other causes of heel pain are suspected i.e. tarsal tunnel syndrome, soft tissue bone tumors, osteomyelitis, subtalar arthritis stress fractures it aids a better more accurate diagnosis.

Initial treatment with rest and non-steroidal anti-inflammatory drugs will suffice to treat majority of cases. When conservative lines of management fail other modalities may be employed [2].

Ball, et al. described a study of 65 patients treated with corticosteroids versus a placebo. They concluded subjective scores in the corticosteroid group showed a clear benefit as compared with the placebo group at 6 weeks and proved effective up till 12 weeks [17].

Genc, et al. used USG in the follow up of 60 patients with similar age, sex and body mass index (BMI) with plantar fasciitis versus a control group without plantar fasciitis. They were assessed with along with the subjective VAS scores and their results showed that steroid injection could be used in the long-term treatment for cases of plantar fasciitis. The study also showed reduction in the thickness of the plantar fascia [18]. 
Increasing evidence of plantar fascia rupture has been reported in literature. Acevedo $\mathrm{Jl}$, et al. concluded that amongst 768 patients 44 had plantar fascia ruptures [19]. John Selman conducted a study on 37 patients with heel pain and observed that one third of the patients had a sudden tearing episode and change in symptoms of patients. This was confirmed by MRI scan showing attenuation of the plantar fascial fibers [8].

Research is being done on PRP and its beneficial effects in chronic tendinopathies as well as treatments in cosmetic, dental and wound healing therapies.

PRP has a role in the inflammatory, coagulation processes as well as immunity modulation. During the degranulation of platelets, they release cytokines and growth factors namely vascular endothelial growth factors; platelet derived growth factors, transforming growth factors, insulin growth factor-1, and hepatocyte growth factor. These promote angiogenesis, help in tissue remodeling and wound healing. They may have a pain-relieving effect depending on the release of proteases with analgesic properties [20].

Ragab EM, et al. studied on 25 patients with plantar fasciitis who underwent treatment with PRP injections. They noted that 22 patients showed subjective improvement and 15 patients had better functional outcome. USG showed significant changes in the thickness of the plantar fascia as well as signal intensity in the region of injection of the PRP [9].

Martinelli N, et al. studied the use of PRP in chronic plantar fasciitis in 14 consecutive patients. They were injected with PRP and subjective scores taken, they were followed up after 12 months. 11 patients had a decrease in the VAS Score. This further substantiates the fact that PRP was a safe alternative and had a potential to decrease the pain due to this condition [21].

Shetty VD, et al. did a subjective and objective study to compare the efficacy of corticosteroid therapy with platelet-rich plasma therapy in recalcitrant plantar fasciitis: A preliminary report concluded that the use of PRP injection can be an attractive alternative in the treatment of disabling, recalcitrant plantar fasciitis [22].

Akşahin Ertuğrul, et al. compared VAS and modified Roles and Maudsley scores. They noted a decrease in the scores in both groups. At 3 weeks and 6 months the two treatments showed no significant difference in VAS and Maudsley scores $(P>0.05)$ [23].

Raymond Rocco Monto performed a study on PRP versus corticosteroids in plantar fasciitis treatment which was confirmed by the MRI scans and radiographs after confirming the diagnosis. This was then scored by the AOFAS score which in the steroid group showed an initial improvement in pain scores but after 6 months' relapse. In the PRP group AOFAS score was persistently high on follow ups concluding that PRP was better than corticosteroids in the treatment of plantar fasciitis [24].

\section{Materials and Methods}

\section{Study type}

Prospective comparative study.

\section{Source}

All the patients with Plantar Fasciitis, who were not better with 6 weeks of conservative treatment presented to the orthopedic department of Justice K.S. Hegde Hospital from August 2014 to Oct 2016 were included in the study after explaining the procedure with consent.

\section{Inclusion criteria}

- Patients aged $18+$.

- Patients with Plantar Fasciitis for at least 6 months which has not responded to 6 weeks of conservative therapy.

- Patients must be able to understand the informed consent and have the ability to follow up.

\section{Exclusion criteria}

- Patients who have had repeated corticosteroid injections within the past 3 months or have taken a non-steroid anti-inflammatory drug during the 1 week prior to receiving an intervention.

- $\mathrm{BMI}$ of $>40$.

- Patients with a previous foot deformity.

- Patients who have had previous foot surgery.

- History of anemia $(\mathrm{Hb}<7)$.

- Pregnancy.

- Significant Cardiovascular, hepatic or renal disease.

- Confirmed diagnosis of neuropathy.

\section{Techniques}

Corticosteroid injection technique: With a $5 \mathrm{cc}$ syringe, $2 \mathrm{~mL}$ of Inj. Depo-Medrol $80 \mathrm{mg}$ (methylprednisolone) along with $1 \mathrm{ml}$ of lignocaine $(0.25 \%)$ is injected into the medial calcaneal tubercle at the point of maximum tenderness using an aseptic technique.

PRP injection technique: A $20 \mathrm{ml}$ sample of venous blood was drawn from the patient's cubital vein under sterile aseptic precautions mixed with $3 \mathrm{ml}$ of citrate phosphate dextrose solution (CPDA).

The mixture was then divided equally into 4 vacutainers.

The sample were then placed in a centrifuge and spun at $3500 \mathrm{rpm}$ for 7 minutes. Using a needle, the buffy coat supernatant layer was removed leaving behind the red and white cell components of the blood.

The collected sample was divided equally into two more vacutainers and spun at $3000 \mathrm{rpm}$ for another 5 minutes and the buffy coat is aspirated and injected into 
Table 1: Intragroup comparison paired T with corticosteroid injection.

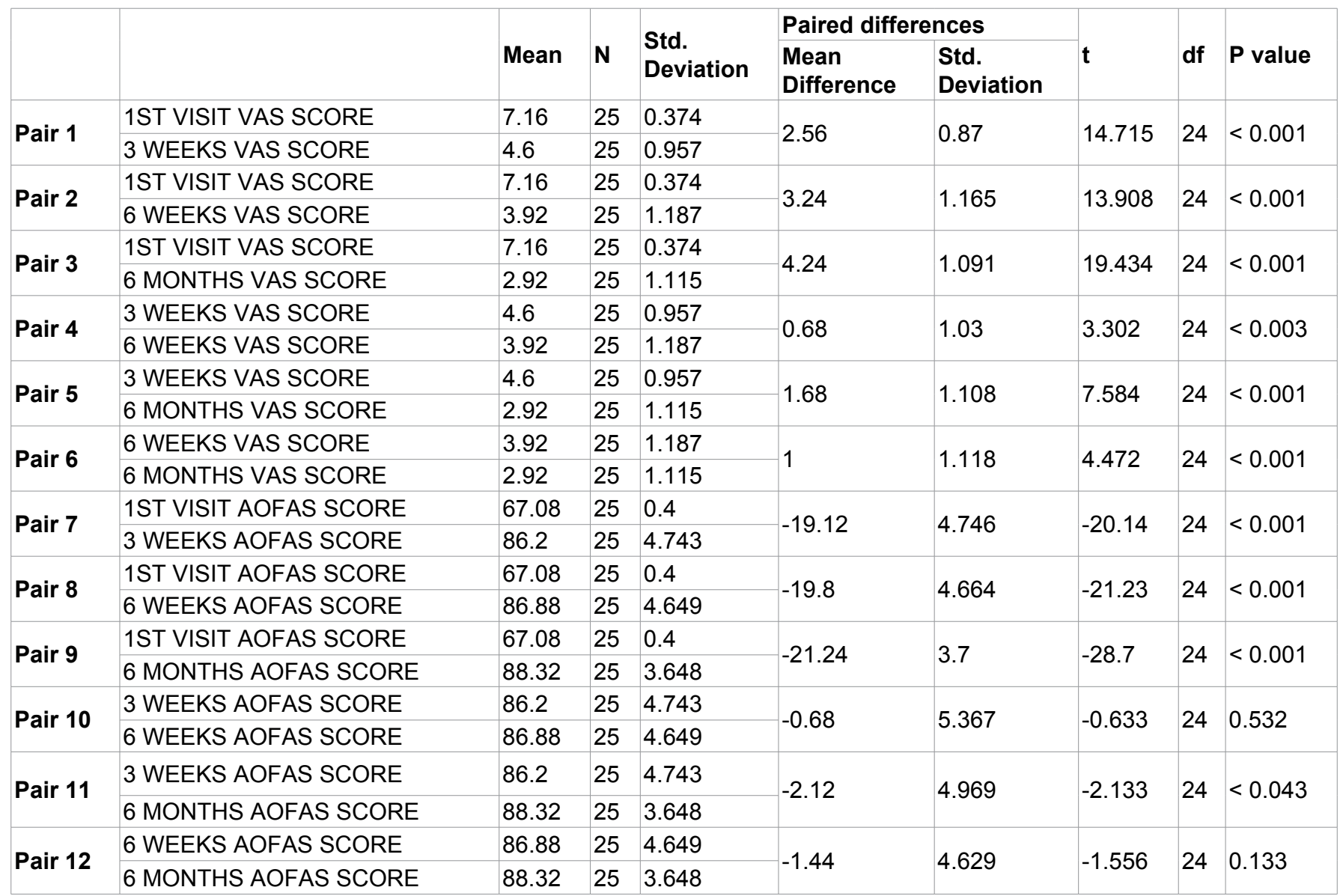

the medial calcaneal tubercle at the point of maximum tenderness.

\section{Assessment of outcome}

- The study follows up requires evaluation at discharge, 6 weeks, 3 months and 6 months. Patient information, including age and sex is noted.

- Functional outcomes for pain, motion and muscle power, and function are assessed using the AOFAS Scoring System and VAS Scoring System.

\section{VAS Scoring System}

- Scale from 0 to 10 based on pain scale.

\section{AOFAS Scoring System}

In this scoring system the pain, function and alignment is graded on a total score of 100 with pain (40 points), function ( 45 points), alignment ( 15 points) were assigned and the objective scoring was done.

\section{Results}

VAS scores between pre-injection and at 3 weeks showed a decrease with a mean difference of 2.56 which is statistically where $p$ value $<0.001$ (Table 1 ).

VAS scores between pre-injection and at 6 weeks showed a decrease with a mean difference of 3.24 which is statistically where $p$ value $<0.001$.

VAS scores between pre-injection and at 6 months showed a decrease with a mean difference of 4.24 which is statistically significant where $p$ value $<0.001$.

VAS scores between 3 weeks and at 6 weeks showed that the score was higher at 3 weeks with a mean difference of 0.68 which is statistically significant where $p$ value $=0.003$.

VAS scores between 3 weeks and at 6 months showed that the VAS at 3 weeks was higher with mean difference of 1.68 which is statistically significant where $p$ value $<0.001$.

VAS scores between 6 weeks and at 6 months showed that the VAS at 6 weeks is higher with a mean difference of 1 which is statistically significant where $p$ value $<0.001$

AOFAS scores between pre-injection and at 3 weeks showed a mean difference of 19.12 is statistically significant increase where $p$ value $<0.001$.

AOFAS scores between pre-injection and at 6 weeks showed a mean difference of 19.8 is statistically significant increase where $p$ value $<0.001$.

AOFAS scores between pre-injection and at 6 months showed a mean difference of 21.24 is statistically significant increase where $p$ value $<0.001$.

AOFAS scores between 3 weeks and at 6 weeks showed an increase with a mean difference of 0.68 but was statistically not significant where $p$ value $=0.532$.

AOFAS scores between 3 weeks and at 6 months 
Table 2: Intragroup comparison paired T test with PRP injection.

\begin{tabular}{|c|c|c|c|c|c|c|c|c|c|c|}
\hline \multirow[b]{2}{*}{ Group } & & & \multirow[b]{2}{*}{ Mean } & \multirow[b]{2}{*}{$\mathbf{N}$} & \multirow[b]{2}{*}{$\begin{array}{l}\text { Std. } \\
\text { Deviation }\end{array}$} & \multicolumn{2}{|c|}{ Paired differences } & \multirow[b]{2}{*}{$\mathbf{t}$} & \multirow[b]{2}{*}{ df } & \multirow[b]{2}{*}{$P$ value } \\
\hline & & & & & & $\begin{array}{l}\text { Mean } \\
\text { Difference }\end{array}$ & $\begin{array}{l}\text { Std. } \\
\text { Deviation }\end{array}$ & & & \\
\hline \multirow[t]{24}{*}{ PRP } & \multirow{2}{*}{ Pair 1} & 1ST VISIT VAS SCORE & 7.24 & 25 & 0.436 & \multirow{2}{*}{1.48} & \multirow{2}{*}{0.82} & \multirow{2}{*}{8.996} & \multirow{2}{*}{24} & \multirow{2}{*}{$<0.001$} \\
\hline & & 3 WEEKS VAS SCORE & 5.76 & 25 & 0.723 & & & & & \\
\hline & \multirow{2}{*}{ Pair 2} & 1ST VISIT VAS SCORE & 7.24 & 25 & 0.436 & \multirow{2}{*}{2.76} & \multirow{2}{*}{1.27} & \multirow{2}{*}{10.887} & \multirow{2}{*}{24} & \multirow{2}{*}{$<0.001$} \\
\hline & & 6 WEEKS VAS SCORE & 4.48 & 25 & 1.194 & & & & & \\
\hline & \multirow{2}{*}{ Pair 3} & 1ST VISIT VAS SCORE & 7.24 & 25 & 0.436 & \multirow{2}{*}{5.64} & \multirow{2}{*}{1.32} & \multirow{2}{*}{21.378} & \multirow{2}{*}{24} & \multirow{2}{*}{$<0.001$} \\
\hline & & 6 MONTHS VAS SCORE & 1.6 & 25 & 1.19 & & & & & \\
\hline & \multirow{2}{*}{ Pair 4} & 3 WEEKS VAS SCORE & 5.76 & 25 & 0.723 & \multirow{2}{*}{1.28} & \multirow{2}{*}{0.98} & \multirow{2}{*}{6.532} & 21 & 10001 \\
\hline & & 6 WEEKS VAS SCORE & 4.48 & 25 & 1.194 & & & & 27 & -0.001 \\
\hline & Pair 5 & 3 WEEKS VAS SCORE & 5.76 & 25 & 0.723 & 4.16 & 114 & 18196 & 24 & $<0,001$ \\
\hline & Fallo & 6 MONTHS VAS SCORE & 1.6 & 25 & 1.19 & 4.10 & 1.14 & 10.190 & 24 & $<0.001$ \\
\hline & Pair 6 & 6 WEEKS VAS SCORE & 4.48 & 25 & 1.194 & 288 & 139 & 1033 & 24 & $<0001$ \\
\hline & railo & 6 MONTHS VAS SCORE & 1.6 & 25 & 1.19 & 2.00 & 1.05 & 10.00 & 24 & -0.001 \\
\hline & Pair 7 & 1ST VISIT AOFAS SCORE & 67.48 & 25 & 0.872 & -1552 & 6.18 & -12559 & 24 & $<0.001$ \\
\hline & & 3 WEEKS AOFAS SCORE & 83 & 25 & 6.344 & & & & & \\
\hline & Pair 8 & 1ST VISIT AOFAS SCORE & 67.48 & 25 & 0.872 & -21.84 & 1.46 & -74.648 & 24 & $<0.001$ \\
\hline & & 6 WEEKS AOFAS SCORE & 89.32 & 25 & 1.435 & & & & & \\
\hline & Pair 9 & 1ST VISIT AOFAS SCORE & 67.48 & 25 & 0.872 & -25.56 & 5.67 & -2256 & 24 & $<0,001$ \\
\hline & I and & 6 MONTHS AOFAS SCORE & 93.04 & 25 & 5.77 & & & $-2<.00$ & 24 & -0.001 \\
\hline & Pair 10 & 3 WEEKS AOFAS SCORE & 83 & 25 & 6.344 & -6 32 & 63 & 5010 & 24 & $<0001$ \\
\hline & rall & 6 WEEKS AOFAS SCORE & 89.32 & 25 & 1.435 & -0.28 & 0.0 & 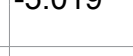 & $<T$ & 5.001 \\
\hline & Pair 11 & 3 WEEKS AOFAS SCORE & 83 & 25 & 6.344 & -1004 & 706 & $-7,108$ & 24 & $<0001$ \\
\hline & 然 & 6 MONTHS AOFAS SCORE & 93.04 & 25 & 5.77 & r. & & 1.100 & & .0 .001 \\
\hline & Pair 12 & 6 WEEKS AOFAS SCORE & 89.32 & 25 & 1.435 & -372 & 6.08 & -3059 & 24 & $<0005$ \\
\hline & $r$ ant 12 & 6 MONTHS AOFAS SCORE & 93.04 & 25 & 5.77 & -0.12 & 0.00 & & & -0.000 \\
\hline
\end{tabular}

showed a mean difference of 2.12 showing an increase which was statistically significant where $p$ value $=0.043$.

AOFAS scores between 6 weeks and at 6 months AOFAS showed an increase with a mean difference of 1.44 and was not statistically significant where $p$ value $=0.133$.

VAS scores at pre-injection and at 3 weeks showed a decrease at 3 weeks with a mean difference of 1.48 which was statistically significant where $p$ value $<0.001$ (Table 2).

VAS at pre-injection and at 6 weeks showed a decrease at 6 weeks with a mean difference of 2.76 which was statistically significant where $p$ value of $<0.001$.

VAS at pre-injection and at 6 months showed a decrease at 6 months with a mean difference of 5.64 which was statistically significant where $p<0.001$.

VAS at 3 weeks and 6 weeks showed that the values at 3 weeks was higher with a mean difference of 1.28 which was statistically significant where $p$ value $<0.001$.

VAS at 3 weeks and 6 months showed that the mean values at 3 weeks was higher with a mean difference of 4.16 which was statistically significant where $p<0.001$.

VAS at 6 weeks and 6 months showed that the values at 6 weeks was higher with a mean difference of
2.88 which was statistically significant with a $p$ value of $<0.001$.

AOFAS Score: AOFAS score between pre-injection and 3 weeks showed an increase at 3 weeks with a mean difference of 15.52 which is statistically significant with a $\mathrm{p}$ value $<0.001$.

AOFAS score between pre-injection and 6 weeks showed an increase at 6 weeks with a mean difference of 21.84 which is statistically significant with a $p$ value of $<0.001$.

AOFAS score between pre-injection and 6 weeks showed an increase at 6 months with a mean difference of 25.56 which is statistically significant with a $p$ value $<$ 0.001 .

AOFAS score between 3 weeks and 6 weeks showed an increase at 6 weeks with a difference of 6.32 which is statistically significant with a $\mathrm{p}$ value $<0.001$.

AOFAS score between 3 weeks and 6 months showed an increase at 6 months with mean difference of 10.04 which is statistically significant with a $p$ value $<0.001$.

AOFAS score between 6 weeks and 6 months showed an increase at 6 months AOFAS is higher with mean difference of 3.72 which is statistically significant with a $p$ value $=0.005$ (Figure 1 and Figure 2). 


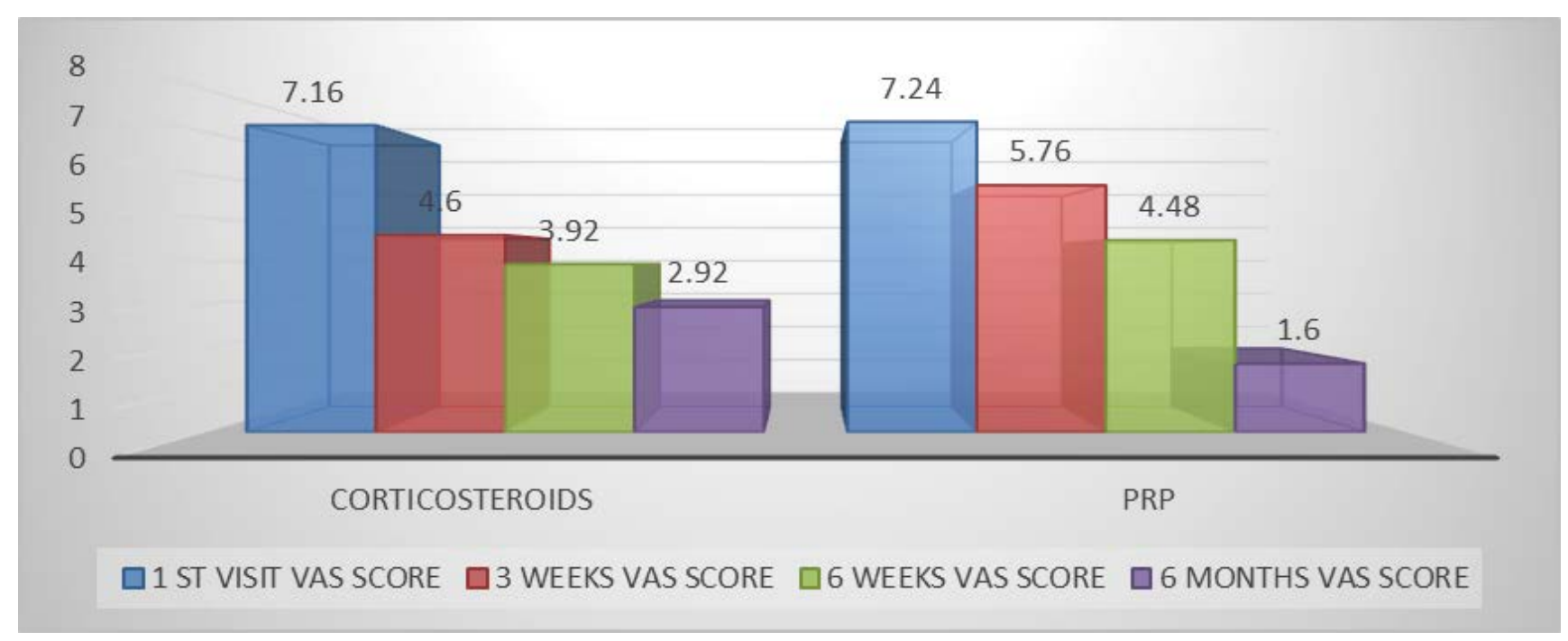

Figure 1: Intragroup visual analogue score comparison.

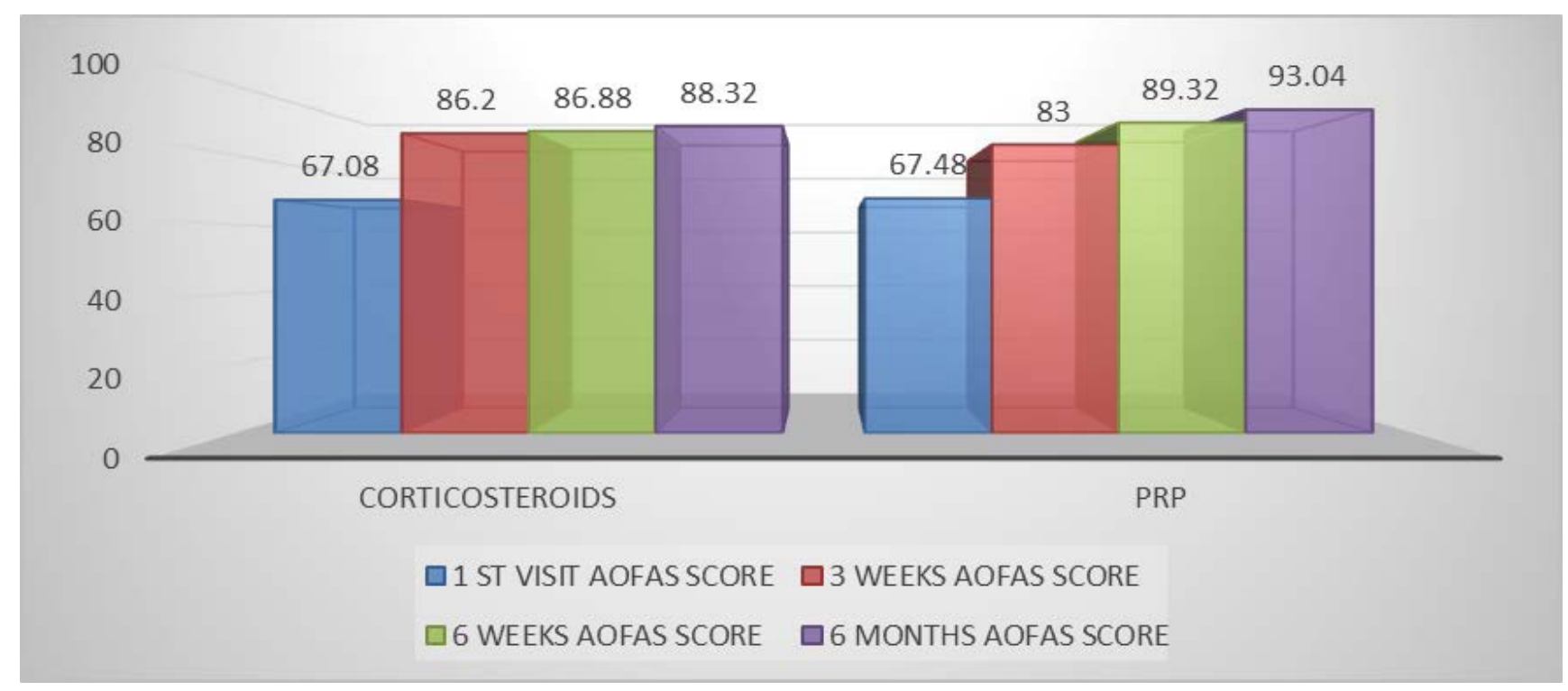

Figure 2: Intragroup American orthopedic foot and ankle score comparison.

Table 3: Intergroup comparison: Independent student $t$ test for VAS score.

\begin{tabular}{|c|c|c|c|c|c|c|c|}
\hline & Group & $\mathbf{N}$ & Mean & $\begin{array}{l}\text { Std. } \\
\text { Deviation }\end{array}$ & $\mathbf{t}$ & df & $P$ value \\
\hline \multirow[t]{2}{*}{ DIFFERENCE IN VAS 3 WEEKS TO 1ST VISIT } & CORTICOSTEROIDS & 25 & 2.56 & 0.87 & \multirow[t]{2}{*}{4.51} & \multirow[t]{2}{*}{48} & \multirow[t]{2}{*}{$<0.001$} \\
\hline & PRP & 25 & 1.48 & 0.823 & & & \\
\hline \multirow[t]{2}{*}{ DIFFERENCE IN VAS 6 WEEKS TO 1ST VISIT } & CORTICOSTEROIDS & 25 & 3.24 & 1.165 & \multirow[t]{2}{*}{1.394} & \multirow[t]{2}{*}{48} & \multirow[t]{2}{*}{0.17} \\
\hline & PRP & 25 & 2.76 & 1.268 & & & \\
\hline \multirow[t]{2}{*}{ DIFFERENCE IN VAS 6 MONTHS TO 1ST VISIT } & CORTICOSTEROIDS & 25 & 4.24 & 1.091 & \multirow[t]{2}{*}{-4.089} & \multirow[t]{2}{*}{48} & \multirow[t]{2}{*}{$<0.001$} \\
\hline & PRP & 25 & 5.64 & 1.319 & & & \\
\hline
\end{tabular}

VAS was compared between pre-injection and at 3 weeks which was higher in corticosteroids with $t$ value of 4.51 and was statistically significant with a $p$ value $<$ 0.001 (Table 3).

VAS was compared between pre-injection and at 6 weeks which was higher in corticosteroids group with a $t$ value of 1.394 and was statistically not significant with a $\mathrm{p}$ value $=0.17$

VAS was compared between pre-injection and at 6 months which was higher in PRP group with a $t$ value of
-4.089 and was statistically significant with a $p$ value $\leq$ 0.001 .

AOFAS was compared between pre-injection and at 3 weeks which was higher in Corticosteroids group with a $t$ value of 2.31 and is statistically significant with a $p$ value $=0.025$ (Table 4) .

AOFAS was compared between pre-injection and at 6 weeks which was higher in the PRP group with a t value of -2.087 and is statistically significant with a $p$ value $=0.046$.

AOFAS was compared between pre-injection and at 
Table 4: Intergroup comparison: Independent student t test for AOFAS score.

\begin{tabular}{|c|c|c|c|c|c|c|c|}
\hline & GROUP & $\mathbf{N}$ & Mean & $\begin{array}{l}\text { Std. } \\
\text { Deviation }\end{array}$ & t & df & $P$ value \\
\hline \multirow[t]{2}{*}{ DIFFERENCE IN AOFAS 3 WEEKS TO 1ST VISIT } & CORTICOSTEROIDS & 25 & 19.12 & 4.746 & \multirow[t]{2}{*}{2.31} & \multirow[t]{2}{*}{48} & \multirow[t]{2}{*}{0.025} \\
\hline & PRP & 25 & 15.52 & 6.179 & & & \\
\hline \multirow[t]{2}{*}{ DIFFERENCE IN AOFAS 6 WEEKS TO 1ST VISIT } & CORTICOSTEROIDS & 25 & 19.8 & 4.664 & \multirow[t]{2}{*}{-2.087} & \multirow[t]{2}{*}{28.677} & \multirow[t]{2}{*}{0.046} \\
\hline & PRP & 25 & 21.84 & 1.463 & & & \\
\hline \multirow[t]{2}{*}{ DIFFERENCE IN AOFAS 6 MONTHS TO 1ST VISIT } & CORTICOSTEROIDS & 25 & 21.24 & 3.7 & \multirow[t]{2}{*}{-3.192} & \multirow[t]{2}{*}{41.324} & \multirow[t]{2}{*}{0.003} \\
\hline & PRP & 25 & 25.56 & 5.665 & & & \\
\hline
\end{tabular}

\section{Chart Title}

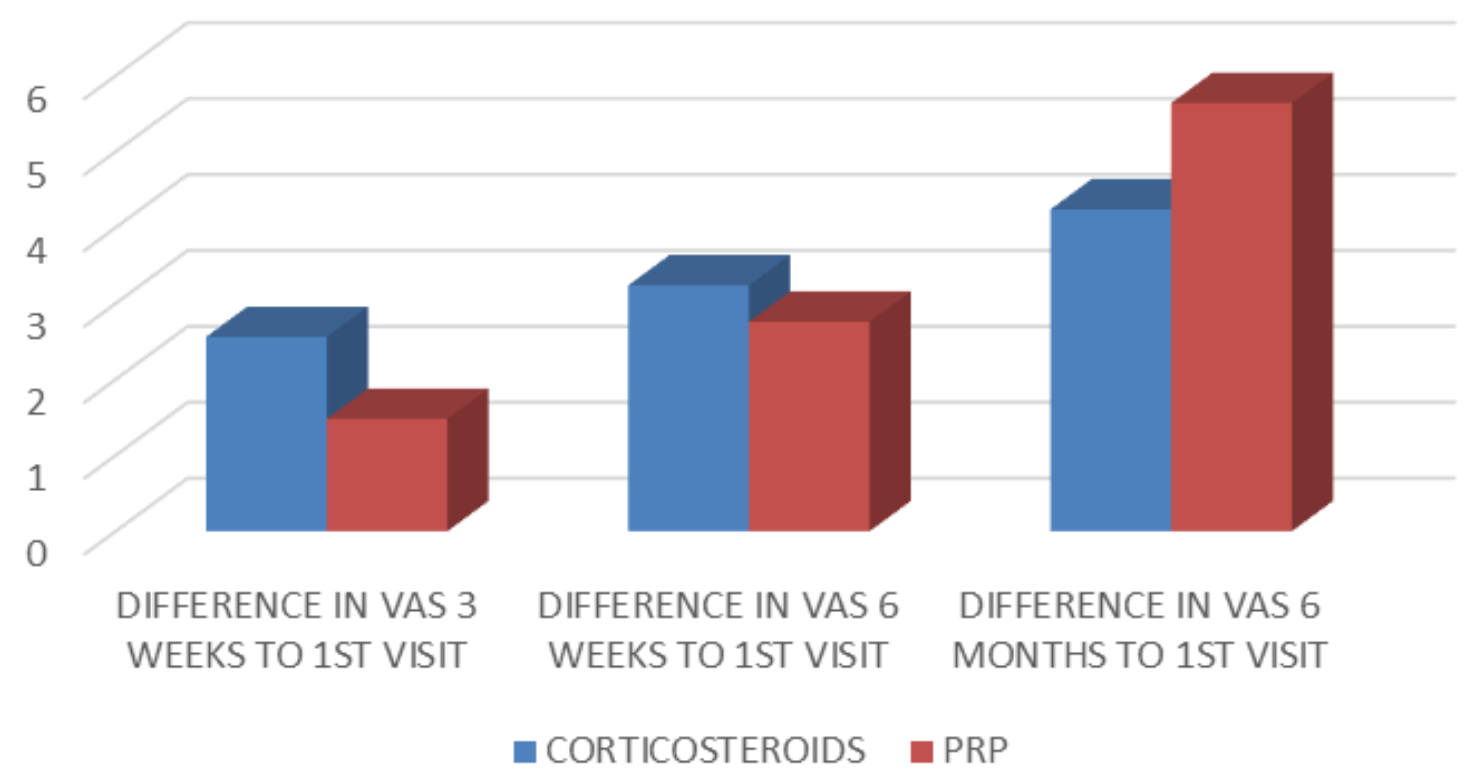

Figure 3: Intergroup visual analogue score comparison.

\section{Chart Title}

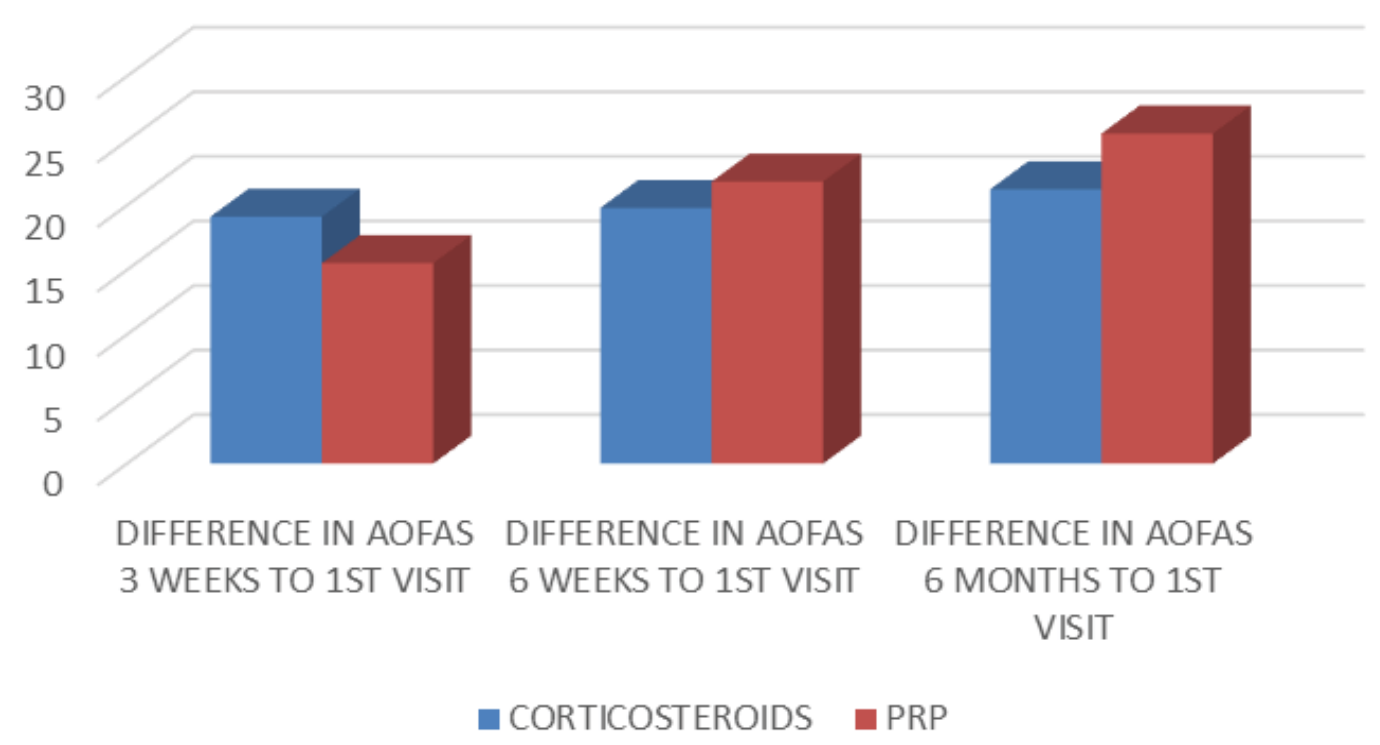

Figure 4: Intergroup American orthopedic foot and ankle score comparison.

6 months which was higher in the PRP group with a t value of -3.192 and is statistically significant with a $p$ value $=0.003$ (Figure 3 and Figure 4).

\section{Discussion}

In our study 50 patients were selected with 25 pa- 
tients each in each group. The VAS and AOFAS scores in each of the groups were assessed individually at the end of our study; we found that both in the Corticosteroid and PRP group there was a significant decrease in the pain and increase in the function as time progressed from the first visit and their consecutive visits at 3 weeks, 6 weeks and 6 months. This was observed by the decreasing VAS Score and increasing AOFAS score in both the groups which was statistically significant $P<0.001$.

When the VAS and AOFAS scores in the corticosteroid group were compared between 3 weeks and 6 weeks, 3 weeks and 6 months and 6 weeks and 6 months we observed that there was a decrease in pain as the time progressed but the AOFAS score between 3 weeks and 6 weeks; 6 weeks and 6 months showed an increase in functionality but was not of any statistical significance with $p=0.53$ and $p=0.13$ respectively.

Similarly, the VAS and AOFAS scores were compared in the PRP group were compared and there was increase in the function of the patient as the time progressed with a $\mathrm{p}<0.001$.

When both the groups were compared there was a higher VAS in the corticosteroid group at 3 weeks $(p<$ 0.001 ) and at 6 weeks VAS was better in the corticosteroid group but with no statistical significance $(p=0.17)$ and VAS was lower in the PRP group $(p<0.001)$.

This was similar to the results that were obtained by Ertuğrul Akşahin, et al. and Shetty VD, et al. who concluded that there was a decrease in the subjective pain score when checked by both VAS and Roles and Maudsley scores in patients treated with PRP.

The AOFAS score showed that there was an increase in function in the corticosteroid group at 3 weeks but at 6 weeks and 6 months there was an increase in function seen in the PRP group.

This was similar to the study by Monto, et al. who demonstrated that both the patients in the PRP and corticosteroids improved up to 3 months and after that the patients who were given PRP did better functionally.

PRP is beneficial in its own ways with less complications but the need of a centrifuging machine which is expensive and is the mainstay for anyone who wants to give PRP in an outpatient set up and thus increasing the cost for giving this; at least 10 times more than corticosteroids.

The shortcomings of the study is absence of a diagnostic tool like a USG scan or an MRI for the confirmation of the diagnosis and the changes noted after the injection which might have provided a better insight to the changes that occur in the plantar fascia and thus quantifying the need for the injection and also the post injection changes in the fascia and the absence of a control arm in this study.

\section{Conclusion}

In this study we concluded that both PRP and Corticosteroids both provides symptomatic relief in the treatment of plantar fasciitis.

PRP proved to be a safe and effective modality in the treatment of this condition with a better functional outcome at the end of the follow up when compared to the patients who had received corticosteroids.

\section{Summary}

PRP and corticosteroids are common modes of treatment of plantar fasciitis which does not respond to conservative treatment. Literature has described the beneficial effects as well as the complications of each of these treatment modalities. Our study compared the pain and the functional outcome who were given any one these treatment modalities. We did a study on 50 patients with 25 patients in each of the group.

Both the groups showed a decrease in pain as the time progressed with no complication observed in any of the group. The patients who were given PRP had a longer duration of pain compared to corticosteroids that had early respite from it.

The functionality in both the groups increased but the patients treated with PRP did better functionally compared to the corticosteroid group.

\section{References}

1. Williams SK, Brage M (2004) Heel pain-plantar fasciitis and achilles enthesopathy. Clin Sports Med 23: 123-144.

2. Cutts S, Obi N, Pasapula C, Chan W (2012) Plantar fasciitis. Ann R Coll Surg Engl 94: 539-542.

3. Ehrenfest D, Rasmusson L, Albrektsson T (2009) Classification of platelet concentrates: From pure platelet-rich plasma (P-PRP) to leucocyte- and platelet-rich fibrin (L-PRF). Trends Biotechnol 27: 158-167.

4. A Moshiri, A Oryan (2012) Role of tissue engineering in tendon reconstructive surgery and regenerative medicine: Current concepts, approaches and concerns. Hard Tissue 1: 11.

5. Lemont H, Ammirati KM, Usen N (2003) Plantar fasciitis: A degenerative process (fasciosis) without inflammation. $\mathrm{J}$ Am Podiatr Med Assoc 93: 234-237.

6. Snider MP, Clancy WG, Mcbeath AA (1983) Plantar fascia release for chronic plantar fasciitis in runners. Am J Sports Med 11: 215-219.

7. Tatli YZ, Kapasi S (2009) The real risks of steroid injection for plantar fasciitis, with a review of conservative therapies. Curr Rev Musculoskelet Med 2: 3-9.

8. Sellman JR (1994) Plantar fascia rupture associated with corticosteroid injection. Foot Ankle Int 15: 376-381.

9. Ragab EM, Othman A (2012) Platelets rich plasma for treatment of chronic plantar fasciitis. Arch Orthop Trauma Surg 132: 1065-1070.

10. Davis PF, Severud E, Baxter DE (1994) Painful heel syndrome: Results of nonoperative treatment. Foot Ankle Int 15: 531-535. 
11. Braddom RL, Buschbacher RM (2007) Physical medicine \& rehabilitation. ( $3^{\text {rd }}$ edn), Saunders Elsevier, Philadelphia.

12. Gill LH (1997) Plantar fasciitis: Diagnosis and conservative treatment. J Am Acad Orthop Surg 5: 109-117.

13. Xu Y, Murrell GA (2008) The basic science of tendinopathy. Clin Orthop Relat Res 466: 1528-1538.

14. Bolgla LA, Malone TR (2004) Plantar fasciitis and the windlass mechanism: A biomechanical link to clinical practice. $J$ Athlet Train 39: 77-82.

15. Orchard J (2012) Plantar fasciitis. BMJ 345: e6603.

16. Monto RR (2013) Platelet-rich plasma and plantar fasciitis. Sports Med Arthrosc Rev 21: 220-224.

17. Ball EM, McKeeman HM, Patterson C, Burns J, Yau WH, et al. (2013) Steroid injection for inferior heel pain: A randomized controlled trial. Ann Rheum Dis 72: 996-1002.

18. Genc H, Saracoglu M, Nacir B, Erdem HR, Kacar M (2005) Long-term ultrasonographic follow-up of plantar fasciitis patients treated with steroid injection. Joint Bone Spine 72: 61-65.
19. Acevedo Jl, Beskin JL (1998) Complications of plantar fascia rupture associated with corticosteroid injection. Foot Ankle Int 19: 91-97.

20. Civinini R, Macera A, Nistri L, Redl B, Innocenti M (2011) The use of autologous blood-derived growth factors in bone regeneration. Clin Cases Miner Bone Metab 8: 25-31.

21. Martinelli N, Marinozzi A, Carnì S, Trovato U, Bianchi $A$, et al. (2013) Platelet-rich plasma injections for chronic plantar fasciitis. Int Orthop 37: 839-842.

22. Shetty VD, Dhillon M, Hegde C, Jagtap P, Shetty S (2014) A study to compare the efficacy of corticosteroid therapy with platelet-rich plasma therapy in recalcitrant plantar fasciitis: A preliminary report. Foot Ankle Surg 20: 10-13.

23. Akşahin E, Doğruyol D, Yüksel HY, Hapa O, Doğan O, et al. (2012) The comparison of the effect of corticosteroids and platelet-rich plasma (PRP) for the treatment of plantar fasciitis. Arch Orthop Trauma Surg 132: 781-785.

24. Monto RR (2014) Platelet-rich plasma efficacy versus corticosteroid injection treatment for chronic severe plantar fasciitis. Foot Ankle Int 35: 313-318. 